TECHNICAL TRANSACTIONS 12/2017

CZASOPISMO TECHNICZNE 12/2017

MECHANICAL ENGINEERING

DOI: $10.4467 / 2353737 X C T .17 .221 .7764$

\author{
Karol Miądlicki (karol.miadlicki@zut.edu.pl,) \\ Mateusz Saków \\ West Pomeranian University of Technology
}

\title{
THE USE OF MACHINE VISION TO CONTROL THE BASIC FUNCTIONS OF A CNC MACHINE TOOL USING GESTURES
}

ZASTOSOWANIE SYSTEMU WIZYJNEGO DO STEROWANIA PODSTAWOWYMI FUNKCJAMI OBRABIARKI CNC ZA POMOCĄ GESTÓW

\begin{abstract}
This paper presents a concept of a vision system which can simplify the way in which some basic functions of CNC machines can be controlled. The proposed system enables the operator to control a machine tool using gestures. The developed solution is based on Microsoft Kinect for a Windows v2 sensor with a time-offlight camera. A gesture recognition module was implemented in the VC 760 milling machine with an open control system (O.C.E.A.N.). To conduct tests of the proposed interface, a set of gestures used to control a CNC machine was developed. Furthermore, the concept, the structure of the system and the test results are discussed. In summary, the advantages and potential problems of the proposed control system and plans for future development are discussed.
\end{abstract}

Keywords: gesture control, Microsoft Kinect, time of flight, machine tool, machine vision

\section{Streszczenie}

W artykule przedstawiona została koncepcja systemu wizyjnego umożliwiającego kontrolowanie i programowanie obrabiarki $\mathrm{CNC}$ za pomocą gestów. Opracowane rozwiązanie ułatwia obsługę obrabiarki CNC poprzez rozpoznawanie gestów wykonywanych przez operatora. Do realizacji sytemu wykorzystany został kontroler ruchu Microsoft Kinect for Windows v2. System rozpoznawania gestów zastosowano w otwartym systemie sterowania obrabiarki VC 760 (O.C.E.A.N.). W ramach badań opracowane zostaly zestawy gestów pozwalających na sterowanie obrabiarką CNC. W artykule omówiono koncepcję i budowę systemu oraz wyniki przeprowadzonych testów. W podsumowaniu wskazano zalety oraz potencjalne problemy związane ze strukturą i zastosowaniem systemu, a także zarysowano plany jego dalszego rozwoju. Słowa kluczowe: sterowanie gestami, Microsoft Kinect, obrabiarki CNC, widzenie maszynowe, systemy wizyjne 


\section{Introduction}

\subsection{Current systems of $\mathrm{CNC}$ machine control}

One of the most sought-after skills on the job market is expertise related to controlling $\mathrm{CNC}$ machine tools and programming machining operations. In recent years, productivity and accuracy of machining has increased in the machine tool industry. Numerous CNC control algorithms have been developed and machine vision systems have been introduced to improve precision and to support the reference positioning of the workpiece. However, methods of communicating with the machine through the operator interface have not been developing at the same rate. Despite developments in the graphic display of CNC interfaces or the introduction of touch panels, the CNC control systems that are currently available on the market are not very intuitive. Manual interfaces still rely on complicated control panels and require knowledge of how to use control systems, Fig. 1 (Siemens, Heidenhein, Fanuc).
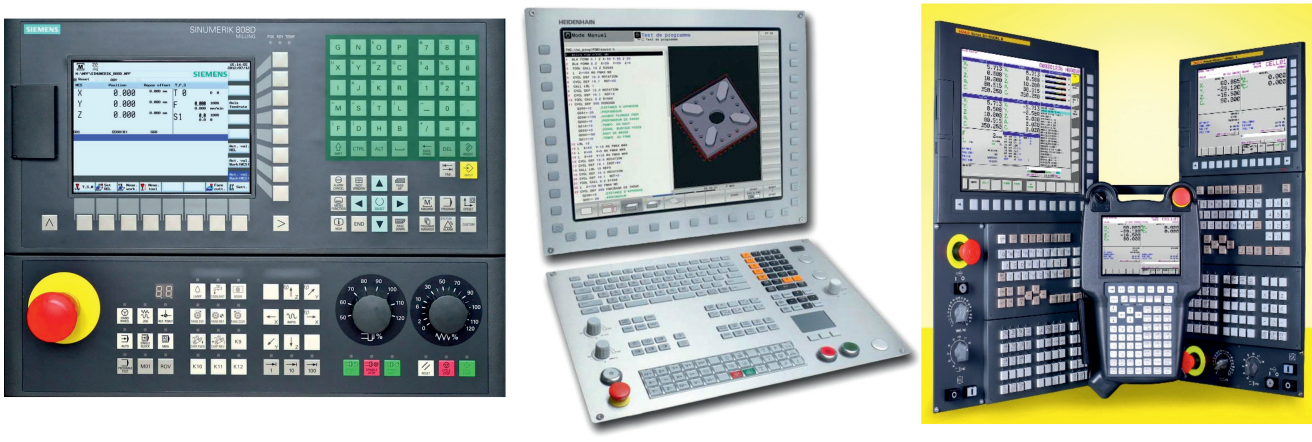

Fig. 1. Operator panel of the most popular CNC systems. From left Sinumerik, Heidenhain, Fanuc

As a consequence of the current nature of manual interfaces it is necessary to learn a set of procedures and key sequences, memorise the functions of diodes and switches, and what actions are triggered by what procedures. Since machines, CNC drivers and operator panels are often configured differently, this only adds to the current difficulties. As a result, the interface between the operator and the machine has become increasingly complex [1]. Only qualified operators can be employed to operate CNC machines - they must go through advanced training to improve their efficiency and minimise the risk of errors.

\subsection{Smart control systems}

With the increasing popularity of computers with huge processing capacity, the development of virtual reality technology and 3D imaging, the application of gestures and human senses to remotely control various machines (haptic feedback) $[2,3]$ seems inevitable [4]. This is evidenced by the current trends on the market of consumer and industrial electronics. While traditional control methods (remote control units, buttons, keys and 
joysticks) seem to be disappearing - new control solutions allowing the use of gestures, voice $[5,6]$ and eyes [7] are more frequently used in game consoles, smartphones and TV sets [8]. The next step in the development of control methods is the full integration of a user with a device through ordinary conversation. This is already being tested on the latest smartphones and computers using voice assistants, for example, Cortana (Microsoft), Siri (Apple) and Google Now (Google Inc.). It is only a question of time before new systems can be implemented into industrial machines.

\subsection{Gesture control systems}

While attempts to modify currently used control systems are being made, other attempts are being made to design virtual environments to use them for remote control purposes in modern factories [9]. These are intended to provide easy and remote operator/machine interaction methods. Gesture control and virtual reality systems might be of interest to the industry. The proper selection of gestures used to give precise commands enables effective and intuitive interaction with machinery without having to be close to it or to learn how to operate a complicated control panel. Gestures and hand-motion control systems can be used for mobile robots, humanoid robots [9], flying robots [10], industrial manipulators [11], electro-hydraulic manipulators [12] and cranes [13-15]. Attempts have been made to use them in surgical robots [16] for controlling data displayed on a monitor without having to touch the keyboard or the mouse [17] as this would ensure maintaining a sterile environment within the operating theatre. In another attempt [18], a virtual environment was used to program a $\mathrm{CNC}$ machine using gestures.

Three dimensional (3D) gesture control systems may be implemented using one of the following methods: vision [19], sound [20], magnetic [21], mechanical [22]. The most commonly used vision method is stereovision. However, active methods based on laser scanning heads (RADAR, LIDAR) $[23,24]$ cameras depth (ToF) or light structure are increasingly being used in many projects. In active vision methods, it is particularly important to obtain information relating to depth. Besides recognising gestures, depth is used to analyse the environment around the machine or locate the position of objects. Despite its popularity

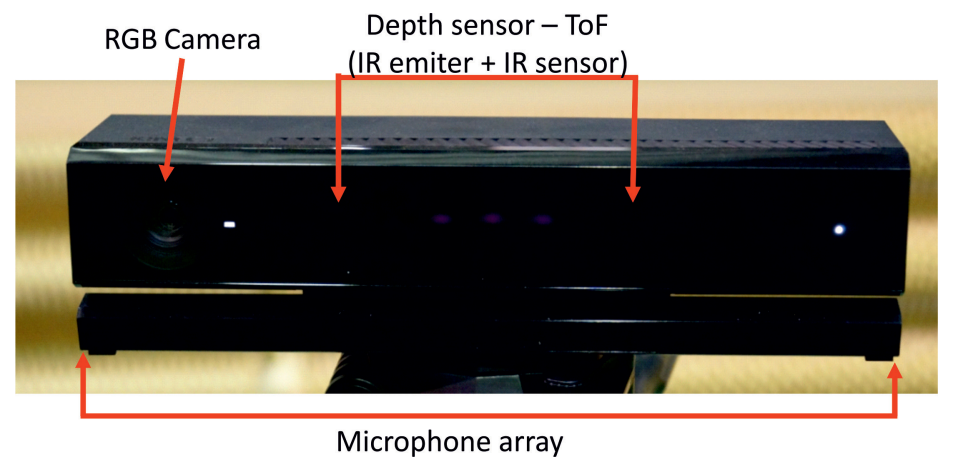

Fig. 2. Microsoft Kinect v2 
and many advantages, optical methods for gesture recognition have several major drawbacks: they require many calculations (stereoscopy), they are expensive (time of flight) and sensitive to external factors (light structure). The effectiveness and reliability of the gesture control system, depends on the precision of the performed gesture and the processing of the gesture signal on each of four or five stages of operation of the system (in the case of tracking systems) [19]. The first important stage is how the user performs a gesture. Here, of particular importance is the accuracy, speed and environment in which the gesture is performed. The gesture is then captured by the sensor (for example, by using a camera, an accelerometer and a magnetic field sensor), which transforms it into a digital signal. The purpose of the following steps (algorithms) is to recognise and classify the received signal (image). Firstly, the image is subjected to segmentation and the feature extraction process.

The segmentation is the process of partitioning a digital image into multiple segments (sets of pixels, also known as super-pixels). The purpose of segmentation is to simplify and change the representation of an image into a form that is more meaningful and easier to analyse. Feature extraction is the process of defining a set of features, or image characteristics, which will most efficiently or meaningfully represent the information that is important for analysis and classification. The real-time tracking system are required to perform these processes and locate a tracking object in every frame of the video sequence. The most commonly used methods for segmentation and feature extraction are based on the skin colour model [25] and static [26] or dynamic [25] background subtraction. These are popular because of their simple implementation and applicability to real-time systems [27]. Some researchers use the infrared camera [28] to extract human I think you should insert another noun here such as 'forms', 'elements' or 'features' here from the frame based on body temperature, as well as more advanced methods based on filters [29] .

The next task of the system is to classify the gesture performed by the operator. Therefore, features are used both before and after object segmentation to provide statistical parameters for classification by a recognition algorithm. A classification or recognition mechanism is a computational algorithm that takes the representation of an object and classifies it as some known class type. The most commonly used techniques for classification are the HMM (hidden Markov model) [30,31] and other statistical methods, ANN (artificial network neutron) [32], methods based on state space [33] wavelet transform [32], matching the curves [34], and database methods [35]. Since the issue of recognition of gestures is currently the subject of intensive research, there are many review papers in which authors present their research in detail and compare algorithms for segmentation, extraction, tracking and classification systems used in gesture recognition.

\subsection{Concept of the proposed control system}

This paper presents the concept of a CNC control system extension for a milling machine based on gesture monitoring and recognition. Its concept is based on tracking operator's gestures using a Microsoft Kinect v2 motion controller (Fig. 2) with a built-in, time-of-flight camera. Data acquired by the system is processed by control algorithms and used for gesture 
recognition. The operator's hand, used as the controller, provides a natural and intuitive control interface. The environments of Kinect Studio, Microsoft Visual Studio, Visual Gesture Builder, Kinect SDK \& Developer Toolkit libraries and C++ programming language were implemented in the system.

\section{Depth sensor}

\subsection{Microsoft Kinect v2}

The Microsoft Kinect sensor was unveiled by Microsoft in November 2010 and it was dedicated for the Xbox 360 game console. This then novel solution enabled its users to interact with their console without having to use pads or other control systems which were common at that time. The system implemented a new interface using hand gestures, body movements and spoken commands. Two years later, Microsoft released Kinect SDK (software development kit) enabling the sensor to cooperate with a PC, and in November 2013, the company launched Kinect $v 2$ together with the new Xbox console.

The sensor is sold with a software package which contains Kinect Studio, Visual Gesture Builder and Kinect SDK 2.0 libraries. The new version of the sensor is more accurate owing to a camera with higher resolution and a ToF camera. This is an important feature since the sensor is used in a variety of professional and semi-professional applications, including advanced medical diagnostics, 3D image analysis (in computer tomography), robotics and IT.

The Kinect sensor consists of six modules: a multi-array microphone, a time-of-flight camera, an infrared emitter, an angularity controller, a USB 3.0 connection lead, and a colour RGB camera. The Kinect sensor has a range of $0.5-4.5$ meters. The lens has an angular field of view of $60^{\circ}$ vertically and $57^{\circ}$ horizontally. The system features four microphones and a 24-bit analogue-to-digital converter which are able to isolate the voices of several users from the ambient noise. The controller uses 48-kHz, 24-bit mono pulse code modulation (PCM).

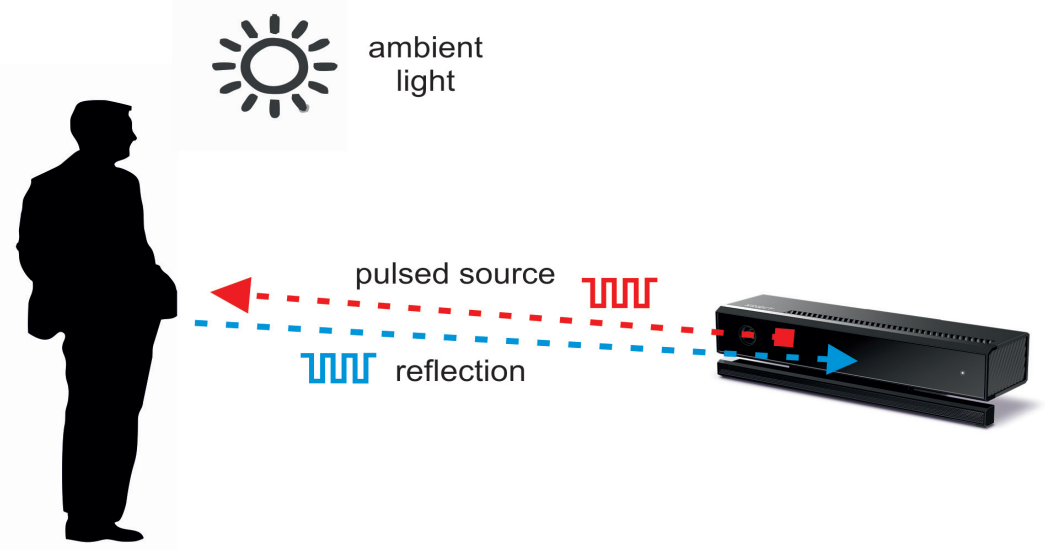

Fig. 3. Operational principles of ToF camera [36] 
The RGB camera features a CMOS sensor and enables user facial recognition and image processing. It operates at $1920 \mathrm{x} 1080 \mathrm{px}$ at $30 \mathrm{fps}$. For depth data input, the sensor interprets the data stream from the time-of-flight camera. It can detect the position of points in $3 \mathrm{D}$ space with a resolution of $512 \times 424$ at $30 \mathrm{fps}$. The 3D time-of-flight camera projects structured light and then gathers the reflected light. Distance is measured by calculating the phase shift between the emitted and received modulated light. The principles of its operation are presented in Fig. 3.

Either a semiconductor laser or LED diodes are usually used as near-infrared light sources $(\sim 850 \mathrm{~nm})$. A modified image sensor then detects reflected light and converts the photonic energy to electrical current [36]. Since Kinect v2 uses a USB 3.0 interface, it supports $2 \mathrm{~Gb} / \mathrm{s}$ data transfer rates. It can simultaneously track six people and 25 skeletal joints per person — including thumbs. It is also capable of detecting a user's pulse, face expression and muscle tension.

\section{System description}

\subsection{Test stand}

A VC 760 milling machine with an open control system (O.C.E.A.N.) [37] developed at the Centre for Mechatronics of the West Pomeranian University of Technology, Szczecin was used for the implementation and testing of the proposed system. O.C.E.A.N system is a conception, of the open, modular, fully reconfigurable and modifiable control system of the CNC cutting machine. The main goal of the system is to introduce an open interface to develop diagnostic functions of the milling machine, implement dynamic and static corrections within the cutting process, extend and test system kernel functions, and introduce new functions to users. The novelty of the system lies in its flexibility and the possibilities for extensions which would improve machining quality.

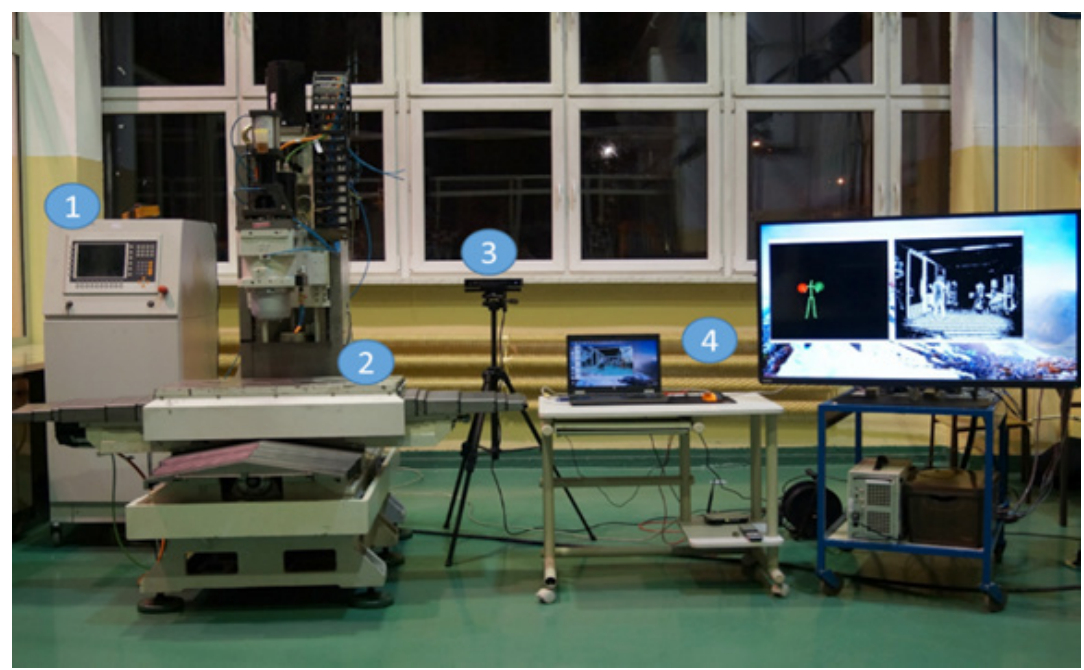

Fig. 4. Test stand 
The VC 760 machine has two kinematic chains of body element movement: object and tool branches. It has screw couplings in 3 axes, with power applied directly from the motor. The test stand is presented in Fig. 4.

This equipment consists of:

1) O.C.E.A.N. control system, based on Acopos intelligent servo drives manufactured by $B \& R$;

2) VC 760 milling machine;

3) Microsoft Kinect v2 sensor;

4) PC used for image processing and communication with the CNC machine.

\subsection{Communication}

The Kinect controller communicates with the milling machine according to the scheme presented in Fig. 5. The control system of the VC 760 milling machine communicates with external devices through an OPC server, operating in the PLC driver (manufactured by B\&R). Positioning data can be sent in two modes:

- Absolute - the table or the workpiece is moved directly to a position defined by ( $\mathrm{x}, \mathrm{y}$, z) coordinates;

- Incremental - the table or the workpiece is moved by a pre-defined vector from its current position $(\Delta \mathrm{x}, \Delta \mathrm{y}, \Delta \mathrm{z})$.

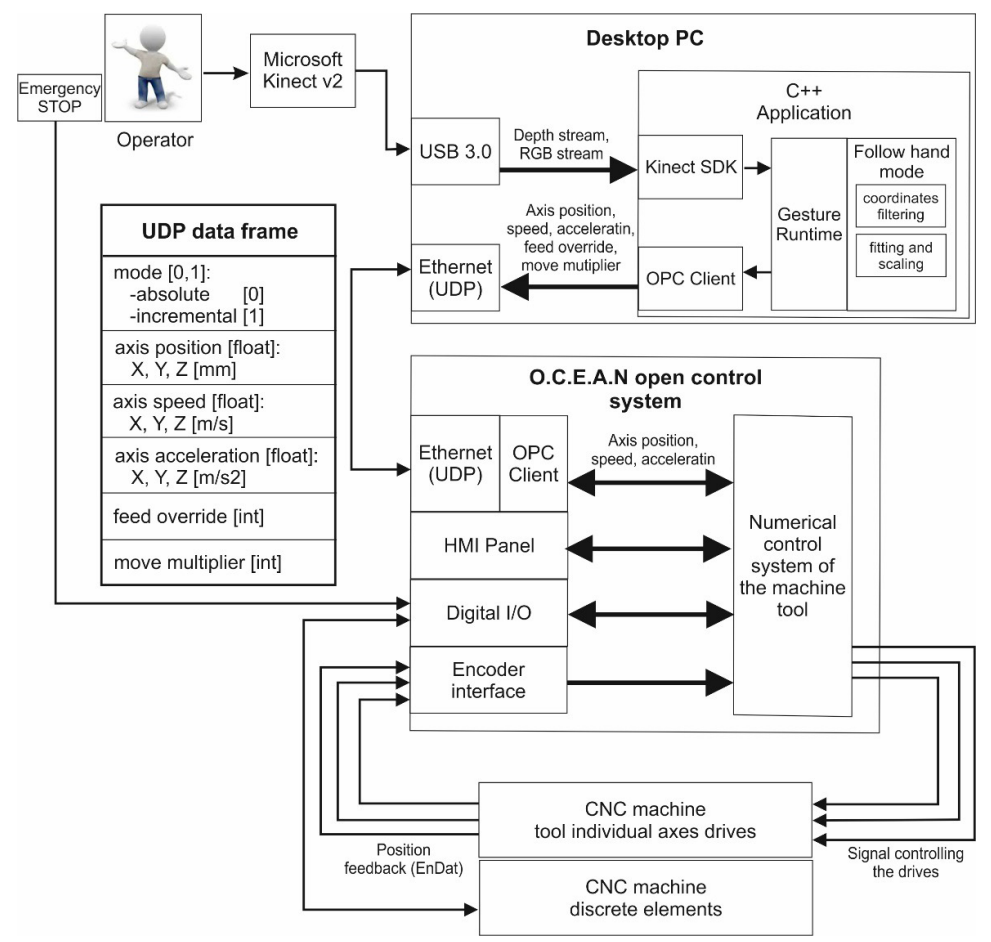

Fig. 5. The communication scheme of the gesture control system 
Coordinates are fed using UDP protocol in specially designed frames. Every frame contains: coordinates, velocity data and acceleration data for each operation, global feed override and the move multiplier. Trajectory is automatically generated by the O.C.E.A.N. control system, based on received points or translations. For safety purposes and to avoid collision, the upper and lower motion ranges for all the axes are fixed. The second part of the program responsible for the Microsoft Kinect sensor operation, gesture recognition and feeding coordinates to the O.C.E.A.N. controller, was written in the Visual Studio 2013 environment using the Kinect for Windows Runtime package: Kinect SDK \& Developer Toolkit library, Kinect Studio and Visual Gesture Builder. Visual Gesture Builder (VGB) is an interactive tool for building models of body gestures using the random forest regression (RFR) machine learning classifier. VGB utilises two detection technologies - AdaBoostTrigger (used to detect discrete gestures) and RFRProgress (used to detect continuous gestures).

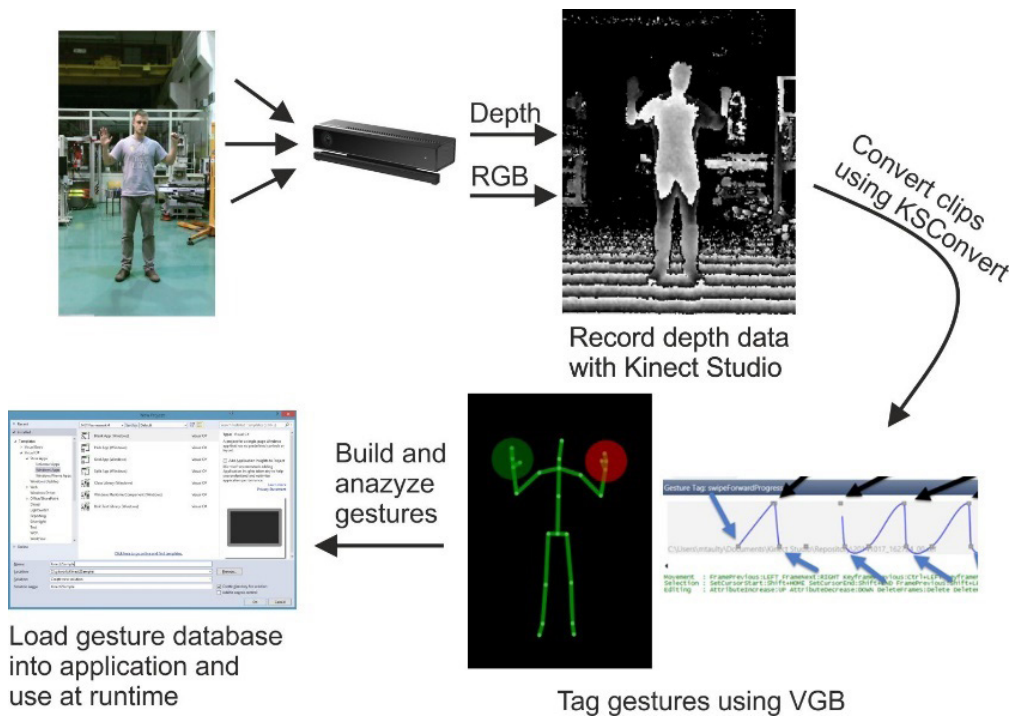

Fig. 6. The data-driven process of creating a gesture detector using Visual Gesture Builder

The developed program consists of five modules responsible for:

- communication with Kinect v2 sensor - receiving data about the position of tracking points

- filtering of received coordinates - smoothing of tracking points using a simple average filter

- gesture recognition - we pre-programmed the gestures described in 3.3. Algorithms implemented directly in Kinect SDK and Visual Gesture Builder were used to detect two gestures. To improve the repeatability of gesture detection, the program was taught by gestures performed by three people of different height and weight. The process of 'learning' gestures is presented in Fig. 6.

- Position, fitting and scaling - this part of the program is responsible for a calibration of the machine's coordinates and the operator's hand. This is critical for safety reasons, as 
without the function, the machine would first make an unknown move to assume the position signalled by the operator's hand.

- Communication with the O.C.E.A.N. controller - sending, receiving and scaling of data about the position of the table and the spindle.

\subsection{Control methods}

Programming of the VC 760 can be performed in manual or semi-automatic mode. Both modes use the appropriate buttons on the control panel, on the remote pedant or G-code commands (numerical control programming language). To perform simple adjustment movements in manual mode, the operator must perform the following operations:

1) move close to the operator panel (HMI)

2) set the following parameters with the appropriate button or command:

c) operating mode - manual

d) axis that will be controlled

e) movement speed

f) positioning accuracy

7) use the appropriate buttons to move the selected axis

Use of the semi-automatic mode in which it is possible to move multiple axes at the same time requires the following steps:

1) move close to the operator panel (HMI)

2) set the following parameters with the appropriate button or command:

c) operating mode - manual

d) axis that will be controlled

e) movement speed

f) positioning accuracy

7) write a program in G-code

8) confirm the code execution with the appropriate buttons

Operation of the CNC in each mode is inconvenient (due to the distance from the machining zone). For this reason, the control pedant is commonly used. This is connected by a flexible cable to the control system of the machine. The remote pedant allows the operator to control the axes movement close to the workpiece but only in manual mode. However, performing positioning moves requiring multiple axes simultaneously, forces the operator to write a simple program in G-code. Using buttons to move the axis is not intuitive because it causes problems such as mistaking different buttons for each other. The use of buttons based interface for the operation of more than one axis is not intuitive and may lead to dangerous situations. A deliberate procedure by constructors is therefore limiting the possibility of using the buttons for one axis only. For the aforementioned reasons, works have been initiated on the development of an intuitive system to control a machine tool using gestures. The idea of a manipulation system for the manual movement of body units of a CNC tool is based on 
gestures sets. This movement should be possible to perform within all the available axes of the machine tool simultaneously. The speed of movement of body elements should be dependent upon the movement speed of the operator's hand.

Three sets of gestures were developed for the purposes of the study. The first set includes four basic gestures to be performed by the left hand: start, stop, confirm and change precision (Fig. 7).

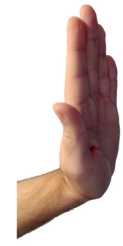

Stop

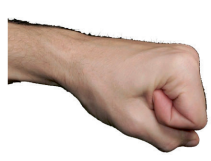

Start

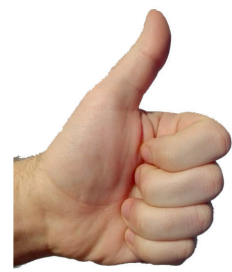

Confirm

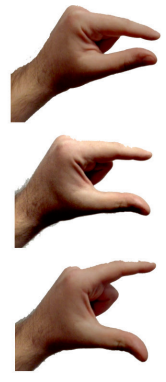

Change Precision

Fig. 7. First set of gestures - basic gestures (for left hand)

The second set is used to control the table and the spindle - the machine follows the right-hand gestures. Hand gestures performed in the air are followed by the table. Up and down gestures control the spindle. The velocity of movement is proportional to the velocity of gestures performed by the operator. The tracking of the operator's hand starts when they clench their right hand into a fist and the operator confirms it by performing the start gesture with their left hand. From now, every hand movement is followed by movement of the machine along the appropriate axis (Fig. 8). An example of the gesture sequence from the second set is shown in Table 1.
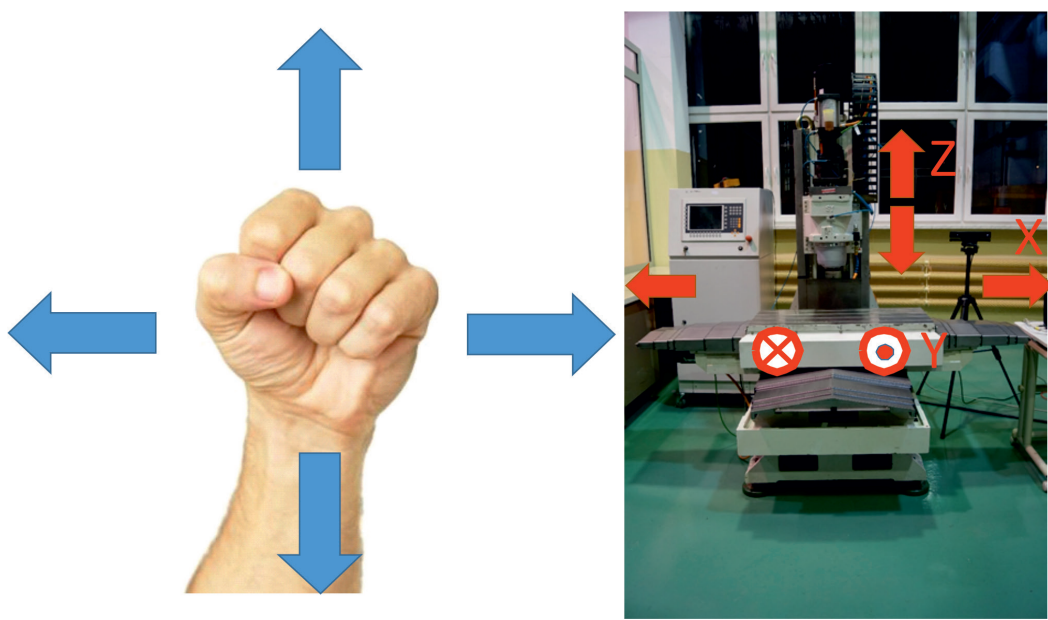

Fig. 8. Axis control in follow mode 
Table 1. An example second set gesture sequence

\begin{tabular}{|c|c|c|c|}
\hline Step & Left Hand & Right Hand & Preformed operation \\
\hline step 1 & & insignificant & $\begin{array}{l}\text { stop machine and cancel all active } \\
\text { tasks }\end{array}$ \\
\hline step 2 & insignificant & & $\begin{array}{l}\text { set machine to be ready and cancel } \\
\text { alarms }\end{array}$ \\
\hline step 3 & & & $\begin{array}{c}\text { activate drives and start following } \\
\text { right hand }\end{array}$ \\
\hline step 4 & \multicolumn{3}{|c|}{ axis movements - following right hand mode (Fig. 7) } \\
\hline step 5 & & insignificant & $\begin{array}{l}\text { stop machine and cancel all active } \\
\text { tasks }\end{array}$ \\
\hline step 6 & insignificant & & $\begin{array}{l}\text { set machine to be ready and cancel } \\
\text { alarms }\end{array}$ \\
\hline step 7 & & & change the precision of movement \\
\hline step 8 & & & confirm change of precision \\
\hline
\end{tabular}




\begin{tabular}{|l|c|c|}
\hline step 9 & \begin{tabular}{|c|c|} 
activate drives and start following \\
right hand with other movement \\
precision
\end{tabular} \\
\hline step 10 & axis movements - following right hand mode (Fig. 7) \\
\hline
\end{tabular}

The third set of gestures is used to select the axis to be controlled. The axis is selected by indicating its number with the fingers. After selecting the axis and confirming it with a 'confirm' gesture, it is possible to control the machine with the right hand clenched into a fist in the tracking mode. An example of the gesture sequence from the third set is shown in Table 2.

Table 2. An example third set gesture sequence

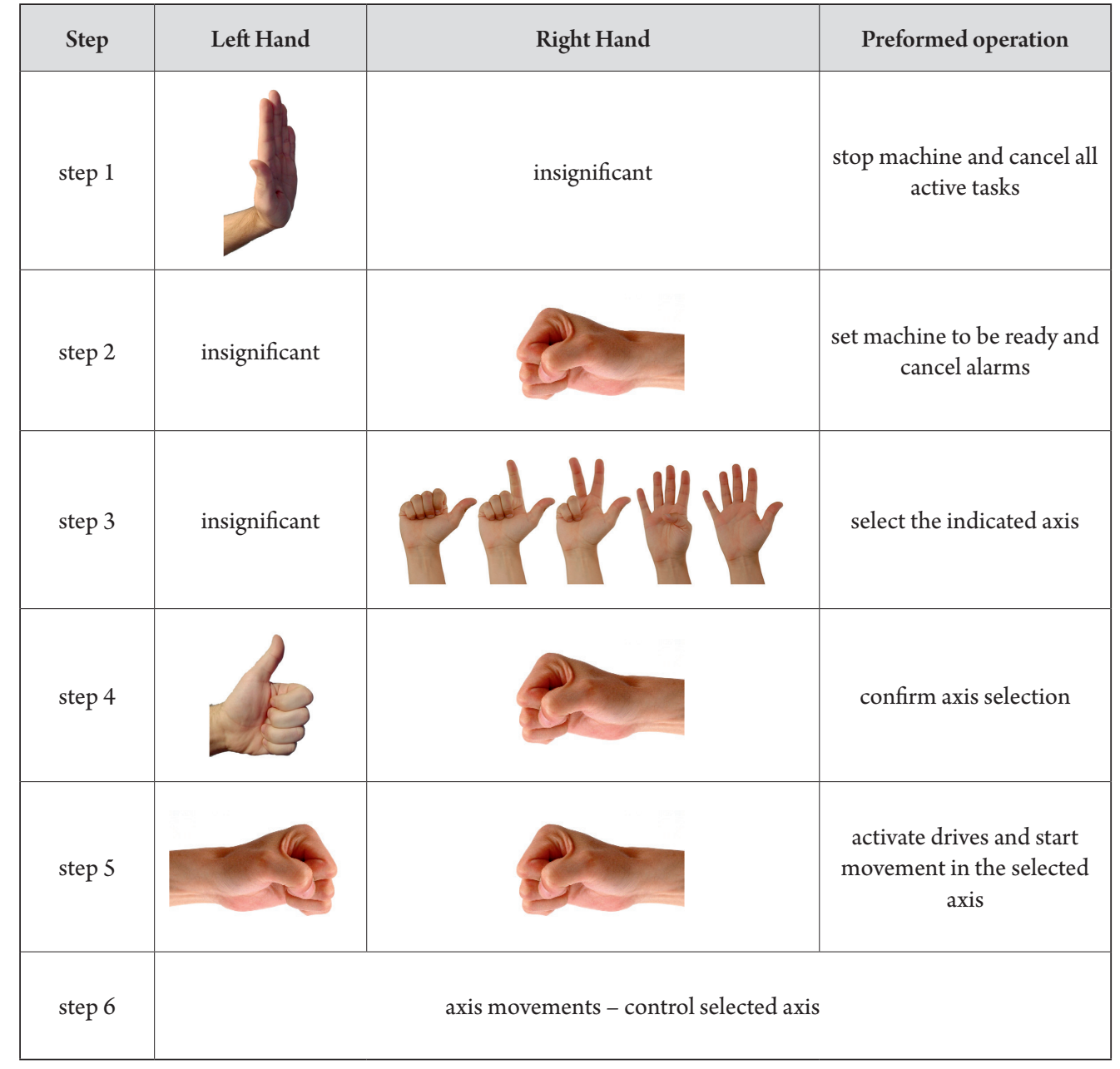




\section{EXPERIMENT RESULTS}

The proposed system was tested on a test stand in the technology hall of the Institute of Materials Science and Engineering, West Pomeranian University of Technology, Szczecin. Experiments revealed that the proposed control system for the VC 760 milling machine was much more intuitive than the standard control panel or the joystick. In the tested system, the operator does not have to know how to use the control panel or command line, or know specific commands. The developed solution only requires the operator to know a basic set of gestures. When the operator takes position in front of the Microsoft Kinect sensor, they are ready to control the VC 760 milling machine. During the operation of the system, the background did not seem to affect its stability. The system could efficiently control the milling machine both with a homogeneous static white background and in a more standard environment (people moving around, objects in the background). The system worked correctly in complete darkness and in poor light conditions. However, a few problems were detected. Firstly, the system was sensitive to intensive light directed at the Kinect v2 sensor. The readings of hand coordinates and gesture detection were either random or assumed maximum values thus rendering proper control of the system impossible. Secondly, the repeatability of gesture detection worsened when the distance between the operator and the sensor was increased or when the operator was located not in front of to the sensor. This issue was observed in gestures involving fingers (axis choice, precision). In some instances, the sensor could not detect gestures when the end of one gesture merged into the beginning of a successive gesture. This problem was probably caused by an inadequate number of samples fed into the sensor during the teaching mode.

Also problematic was occlusion (moment when the hand being obscured) and gestures being performed at too great a speed. Because the hand is a complicated object with more than twenty DOF, it can have many different shapes and positions. Recognising them is particularly difficult, this is due to the mutual shadowing of the palm and fingers which hinders segmentation/extraction and consequently, the recognition of precise gestures. In addition, the speed of a moving hand is high and can reach up to $5 \mathrm{~m} / \mathrm{s}$ in linear displacement and 300 $\mathrm{deg} / \mathrm{s}$ in wrist rotation [38]. These factors necessitate either the use of high-speed cameras or advanced algorithms for slower cameras. This is related to delays during gesture recognition due to the problem of processing large amounts of data in real time. Average error rate for stop, start and confirm gestures was $10 \%$ for false positive errors and 5\% for false negatives. Worse results were obtained for change precision gestures - $22 \%$ (false positives) and $9 \%$ (false negatives). Another problem was the control of the machine when the operator was close to the worktable. This is a very difficult situation for the system, because the operator is, to a large degree, obscured by the machine and is thus not visible to the sensor. Solving this problem requires further research and will probably enforce the use of an additional sensor for tracking the operator when working close to the machine. Due to the possibility of a collision of the machine with the operator, incorrect gesture recognition or uncontrolled movement of the operator, programmed axis limits were applied. In addition, the operator was equipped with a safety button which triggers the immediate activation of the brake motors. At the start 
of the study, a hand switch was used; however, it was decided to use a foot switch during the tests for ergonomic reasons. After all, the problem of incorrect movements or gesture classification is much more complex and requires deeper analysis and more comprehensive solutions than simply having a safety button. Thus, the safety system for the gesture control system will be the subject of further research.

Since the main aim of the research was to test the possibility of using gesture control to operate CNC machines, at this stage of the project, the precision with which an operator can control the machine tool was not measured. However, based on research on Kinect v2 [39], it is possible to estimate the Kinect distance sensor accuracy. Depth accuracy in the middle of the sensor operating range (1000-2000 mm) is marked as: $\pm 2 \mathrm{~mm}$, while the at the ends of the range is marked as: $\pm 4 \mathrm{~mm}$. Additionally, changing movement resolution (feed override - a gesture change), the operator can obtain leverage effects. Hand movements in the range of $1-1000 \mathrm{~mm}$, will move an appropriately selected axis by $0.001-1 \mathrm{~mm}$. A similar solution is used in $\mathrm{CAD}$ software. Very precise parts are designed using an inaccurate computer mouse.

Given the purposes of the system, the values are sufficient for tasks such as pre-positioning the machine, tool setting and referencing the. It is also possible to apply additional support functions.

\section{Summary}

The paper presents and discusses the concept and the constituent elements of the proposed system and test results. The advantages and potential problems of the system are shown. Based on the conducted research and test results, a conclusion can be drawn that effective gesture control requires the careful and thoughtful selection of gestures. Gestures should be able to convey precise control signals. Therefore, gestures should be simple and intuitive for the operator. They should not cause problems with their recognition as this may lead to undesirable delays and latency in the system. The tests demonstrated that the Microsoft Kinect $\mathrm{v} 2$ sensor, which is dedicated to computer games, was quite efficient at communicating with the control system of the CNC machine tool and properly detected simple gesture commands. The presented results only reveal the potential of gesture control. An industrial implementation of a gesture control system would involve the use of professional tracking systems and advanced program functions that support various technological aspects of the programming $\mathrm{CNC}$ machine tools. To eliminate control panels, future systems would also feature voice control and augmented reality systems.

In this paper, a new approach to control basic function of CNC machines which uses the technology vision and gesture recognition has been proposed. The proposed core set of gestures do not allow the use of all possibilities and options of advanced CNC control systems, because the aim of the research is not to replace complex operator panels but add new capabilities to the $\mathrm{CNC}$ system and facilitating simple control movements. The G-code programming procedure is complicated, especially without access to the keyboard. Therefore, 
the complete replacement of the operator panel with the control system of gestures still requires a lot of research.

The proposed system extension represents a new approach with regard to CNC machine control. It uses vision and gesture recognition technologies. Although it has some drawbacks, it undoubtedly has a significant advantage - it is very intuitive and does not require $\mathrm{CNC}$ operators and programmers to undergo difficult and long-lasting training. It also allows the simultaneous use of a traditional control panel.

This project is financed by the National Centre for Research and Development, Poland (NCBiR), under the Applied Research Programme - Grant agreement No. PBS3/A6/28/2015 and Dean's Grant for Young Scientists No. 517-06$011-5404 / 17$

\section{References}

[1] Shuo-Peng L., Hsu J., Chun-Chien T., Development of the common human-machine interface for multi-axis machine tools, IEEE/ASME International Conference on Advanced Intelligent Mechatronics (AIM), Kaohsiung, Taiwan, 2012, 650-653.

[2] Saków M., Miądlicki K., Parus A., Self-sensing teleoperation system based on 1-dof pneumatic manipulator, Journal of Automation Mobile Robotics and Intelligent Systems, Vol. 11, 64-76.

[3] Saków M., Parus A., Pajor M., Miądlicki K., Nonlinear inverse modeling with signal prediction in bilateral teleoperation with force-feedback, Methods and Models in Automation and Robotics (MMAR), Międzyzdroje, 2017, 141-146.

[4] Kopp S., Wachsmuth I., Gesture in Embodied Communication and Human Computer Interaction, 1 ed., Springer-Verlag, Berlin 2010.

[5] Majewski M., Kacalak W., Smart Control of Lifting Devices Using Patterns and Antipatterns, [in:] Artificial Intelligence Trends in Intelligent Systems: Proceedings of the 6th Computer Science On-line Conference, R. Silhavy, R. Senkerik, Z. Kominkova-Oplatkova, Z. Prokopova, P. Silhavy (Eds.), Springer International Publishing, Cham 2017.

[6] Majewski M., Kacalak W., Innovative Intelligent Interaction Systems of Loader Cranes and Their Human Operators, [in:] Artificial Intelligence Trends in Intelligent Systems: Proceedings of the 6th Computer Science On-line Conference, R. Silhavy, R. Senkerik, Z. Kominkova-Oplatkova, Z. Prokopova, P. Silhavy (Eds.), Springer International Publishing, Cham 2017.

[7] Corcoran P., To Gaze with Undimmed Eyes on All Darkness [IP Corner], IEEE Consumer Electronics Magazine, Vol. 4, 99-103.

[8] Jing Y. et al., A novel hand gesture input device based on inertial sensing technique, 30th Annual Conference of IEEE Industrial Electronics Society (IECON), Busan, South Korea 2004, Vol. 3, 2786-2791.

[9] Almetwally I., Mallem M., Real-time tele-operation and tele-walking of humanoid Robot Nao using Kinect Depth Camera, 10th IEEE International Conference on Networking, Sensing and Control (ICNSC), Evry, France 2013, 463-466. 
[10] Sanna A., Lamberti F., Paravati G., Manuri F., A Kinect-based natural interface for quadrotor control, (in en), Entertainment Computing, Vol. 4, 179-186.

[11] Pajor M., Miądlicki K., Saków M., Kinect sensor implementation in FANUC robot manipulation, Archives of mechanical technology and automation, Vol. 34, 35-44.

[12] Gośliński J., Owczarek P., Rybarczyk D., The use of Kinect sensor to control manipulator with electrohydraulic servodrives, Pomiary, Automatyka, Robotyka, Vol. 17, 481-486.

[13] Pietrusewicz K., Miądlicki K., Gestures can control cranes, Control Engineering, Vol. 61, 14.

[14] Majewski M., Kacalak W., Budniak Z., Pajor M., Interactive Control Systems for Mobile Cranes, [in:] Advances in Intelligent Systems and Computing, Vol. 661, ed, 2018, 10-19.

[15] Majewski M., Kacalak W., Human-Machine Speech-Based Interfaces with Augmented Reality and Interactive Systems for Controlling Mobile Cranes, Interactive Collaborative Robotics: First International Conference, Budapest 2016, 89-98.

[16] Liu W., Ren H., Zhang W., Song S., Cognitive tracking of surgical instruments based on stereo vision and depth sensing, IEEE International Conference on Robotics and Biomimetics (ROBIO), Shenzhen, China 2013, 316-321.

[17] Gallo L., Placitelli A., Ciampi M., Controller-free exploration of medical image data: Experiencing the Kinect, 24th International Symposium on Computer-Based Medical Systems (CBMS), Bristol, United Kingdom 2011, 1-6.

[18] Stateczny K., Pajor M., Project of a manipulation system for manual movement of CNC machine tool body units, Advances in Manufacturing Science, Vol. 35, 33-41.

[19] Berman S., Stern H., Sensors for Gesture Recognition Systems, IEEE Transactions on Systems, Man, and Cybernetics, Part C (Applications and Reviews), Vol. 42, 277-290.

[20] Kalgaonkar K., Raj B., One-handed gesture recognition using ultrasonic Doppler sonar, IEEE International Conference on Acoustics, Speech and Signal Processing (ICASSP), Taipei, Taiwan 2009, 1889-1892.

[21] Ketabdar H., Ali K., Roshandel M., MagiTact: interaction with mobile devices based on compass (magnetic) sensor, 15th international conference on Intelligent user interfaces, Hong Kong, China 2010, 413-414.

[22] Pajor M., Stateczny K., Pietrusewicz K., Virtual reality applied for programming CNC machine tools, Control Engineering, Vol. 60, 50.

[23] Miądlicki K., Pajor M., Saków M., Ground plane estimation from sparse LIDAR data for loader crane sensor fusion system, Methods and Models in Automation and Robotics (MMAR), Międzyzdroje 2017, 717-722.

[24] Miądlicki K., Pajor M., Saków M., Real-time ground filtration method for a loader crane environment monitoring system using sparse LIDAR data, Innovations in Intelligent SysTems and Applications (INISTA), Gdynia 2017, 207-212.

[25] Shuying Z., Li S., Wenjun T., A method of dynamic hand gesture detection based on local background updates and skin color model, International Conference on Computer Application and System Modeling (ICCASM), Taiyuan, China 2010, Vol. 5, V5-657-V5-660. 
[26] Mohan P., Srivastava S., Tiwari G., Kala R., Background and skin colour independent hand region extraction and static gesture recognition, Eighth International Conference on Contemporary Computing (IC), Noida, India 2015, 144-149.

[27] Haiting Z., Xiaojuan W., Hui H., Research of a Real-time Hand Tracking Algorithm, International Conference on Neural Networks and Brain (ICNNB), Beijing, China 2005, Vol. 2, 1233-1235.

[28] Ionescu D., Suse V., Gadea C., Solomon B., Ionescu B., Islam S., An infrared-based depth camera for gesture-based control of virtual environments, IEEE International Conference on Computational Intelligence and Virtual Environments for Measurement Systems and Applications (CIVEMSA), Milan, Italy 2013, 13-18.

[29] Feng Z., Du P., Song X., Chen Z., Xu T., Zhu D., Research on Features Extraction from Frame Image Sequences, International Symposium on Computer Science and Computational Technology (ISCSCT), Shanghai, China 2008, Vol. 2, 762-766.

[30] Nianjun L., Lovell B. C., Kootsookos P.J., Davis R. I. A., Model structure selection \& training algorithms for an HMM gesture recognition system, Ninth International Workshop on Frontiers in Handwriting Recognition (IWFHR), Tokyo, Japan 2004, 100-105.

[31] Liu K., Chen C., Jafari R., Kehtarnavaz N., Multi-HMM classification for hand gesture recognition using two differing modality sensors, Circuits and Systems Conference (DCAS), Dallas, USA 2014, 1-4.

[32] Fu X., Lu J., Zhang T., Bonair C., Coats M. L., Wavelet Enhanced Image Preprocessing and Neural Networks for Hand Gesture Recognition, IEEE International Conference on Smart City/SocialCom/SustainCom, Chengdu, China 2015, 838-843.

[33] Watanabe T., Yachida M., Real time gesture recognition using eigenspace from multi-input image sequences, Third IEEE International Conference on Automatic Face and Gesture Recognition, Nara, Japan 1998, 428-433.

[34] Shehu V., Dika A., Curve similarity measurement algorithms for automatic gesture detection systems, 35th International Convention on Information and Communication Technology, Electronics and Microelectronics, Opatija, Croatia 2012, 973-976.

[35] Chen M., AlRegib G., Juang B.H., A new 6 D motion gesture database and the benchmark results of feature-based statistical recognition, IEEE International Conference on Emerging Signal Processing Applications (ESPA), Las Vegas, USA 2012, 131-134.

[36] Van Nieuwenhove D., Van der Tempel W., Grootjans R., Kuijk M., Time-of-flight Optical Ranging Sensor Based on a Current Assisted Photonic Demodulator, Annual Symposium of the IEEE Photonics Benelux Chapter, Ghent, Belgium 2006, 209-212.

[37] Domek S., Pajor M., Pietrusewicz K., Urbański Ł., Experimental open control system OCEAN for linear drives, Inżynieria Maszyn, Vol. 16, 40-49.

[38] Erol A., Bebis G., Nicolescu M., Boyle R.D., Twombly X., Vision-based hand pose estimation: A review, Computer Vision and Image Understanding, Vol. 108, 52-73.

[39] Wang Q. Kurillo G., Ofli F., Bajcsy R., Evaluation of Pose Tracking Accuracy in the First and Second Generations of Microsoft Kinect, International Conference on Healthcare Informatics (ICHI), Dallas, USA 2015, 380-389. 